Proceedings

\title{
Novel Biodegradable Polyanhydrides Based on Betulin Disuccinate and Sebacic Acid for Medical Purpose $^{\dagger}$
}

\author{
Daria Niewolik ${ }^{1, *}$, Barbara Bednarczyk-Cwynar ${ }^{2}$, Piotr Ruszkowski ${ }^{3}$ and Katarzyna Jaszcz ${ }^{1}$ \\ 1 Department of Physical Chemistry and Technology of Polymers, Silesian University of Technology, M. \\ Strzody 9, 44-100 Gliwice, Poland; Katarzyna.Jaszcz.@polsl.pl \\ 2 Department of Organic Chemistry, Poznan University of Medical Science, Grunwaldzka 6, 60-780 Poznan, \\ Poland; bcwynar@ump.edu.pl \\ 3 Department of Pharmacology, Poznan University of Medical Science, Rokietnicka 5a, 60-806 Poznan, \\ Poland; pruszkowski@gmail.com \\ * Correspondence: Daria.Niewolik@polsl.pl \\ † Presented at the 1st International Electronic Conference on Applied Sciences, 10-30 November 2020; \\ Available online: https://asec2020.sciforum.net/.
}

Published: 10 November 2020

\begin{abstract}
The paper describes synthesis and the characterization of novel biodegradable betulinbased polyanhydrides, exhibiting anti-cancer activity. Polyanhydrides were obtained by a melt polycondensation of a disuccinate betulin (3,28-di-O-succinyl betulin) and sebacic acid with the use of acetic anhydride. Mentioned polyanhydrides were then thoroughly characterized by ${ }^{1} \mathrm{H}$ NMR and ${ }^{13} \mathrm{C}$ NMR, size exclusion chromatography, differential scanning calorimetry and FT-IR spectroscopy. The content of sebacic acid in obtained copolymers was from 20 to $80 \mathrm{wt} \%$. The use of sebacic acid as a comonomer increases the crystallinity of polymers. Under physiological conditions copolymers undergo hydrolytic degradation to betulin disuccinate, whose biological activity is known and confirmed and to sebacic acid approved by FDA for use in drug delivery systems. Polyanhydrides were also tested for cytostatic activity against a wide range of cancer cell lines (HeLa, A-549, U-87MG, KB and HepG2), proving its efficiency in inhibiting the growth of selected cell lines. Obtained polymers can be used as carriers in drug delivery system, in form of microspheres. Microspheres with diameter within the range of $D_{n}=15-30 \mu \mathrm{m}$ were prepared by using emulsion $(\mathrm{O} / \mathrm{W})$ solvent evaporation method.
\end{abstract}

Keywords: betulin; polyanhydrides; biodegradable polymer; cytotoxic activity

\section{Introduction}

Polymers obtained from renewable raw materials are a valuable group of compounds that are used in many industries, including the pharmaceutical ones. With the growing interest in biopolymers, there is a need to find new natural monomers that can replace petroleum-based raw materials. Natural monomers used for polymerization include furans, terpenes and lactic acid [1]. Compared to polymers based on furan and lactic acid, much less attention is paid to the polymerization of terpenes. Terpenes are compounds widely occurring in nature, produced by a variety of plants and animals. They show a broad spectrum of biological activity [2]. One of these natural triterpenes is betulin. Betulin, a pentacyclic triterpene, occurs in nature, e.g., in the outer layer of birch bark. Both betulin and its derivatives, e.g., betulin disuccinate, exhibit a broad spectrum of biological activity, including anticancer activity, while being non-toxic to normal cells [3]. Due to the presence of functional groups, betulin is an ideal substrate for the preparation of polymers. Polymeric 
betulin derivatives described so far in the literature include polyesters [1], polyurethanes [4] and polyethylene oxide conjugates [5]. Recently, we have obtained a polyanhydride of betulin disuccinate (DBB), exhibiting anti-cancer activity, that can be used in drug delivery systems [6].

Polyanhydrides, a biodegradable polymers, easily undergo hydrolytic degradation to their respective diacid which are completely eliminated from the body within a short period of time. They are mainly used in medicine, both as drug carriers and as biomaterials [7]. Due to the fact that DBB has biological activity, e.g., antitumor activity, the polyanhydride obtained therefrom can be used as a polymeric prodrug that releases the active substance (DBB) as a result of polymer hydrolysis under physiological conditions, or as a non-toxic carriers of other biologically active substances. The rate of polymer hydrolysis, and thus DBB release, can be controlled by copolymerization with other diacids. Copolymerization also allows the modification of the physicochemical properties of the polymers. The aim of this work was the synthesis and characterization of polyanhydrides composed of betulin disuccinate and sebacic acid. In our case, the use of sebacic acid as a comonomer increases the crystallinity of the polyanhydrides and influences the rate of hydrolytic degradation. Depending on the composition of polyanhydrides, the difference of degradation behaviour can be used to influence release profiles of therapeutic molecules. In order to determine the anti-cancer activity of copolymers, these materials were tested for cytotoxicity against a wide range of cancer cell lines, including HeLa, A-549, U-87MG, KB and HepG2.

\section{Materials and Methods}

\subsection{Materials}

Betulin disuccinate (obtained in the laboratory according to the procedure described in the article [6]), acetic anhydride (POCh S.A.), sebacic acid (ACROS Organics), DMSO (Chempur), trichloroacetic acid (Chempur), acetic acid (Chempur), Tris buffer, sulforhodamine, poly(vinyl alcohol) ( $\mathrm{M}_{\mathrm{w}}=88,000 \mathrm{~g} / \mathrm{mol}, 88 \%$ hydrolyzed) (ACROS Organics), methylene chloride (Chempur) were used as supplied.

KB, HeLa and Hep-G2 cells were obtained from the European Collection of Cell Culture (ECACC) supplied by Sigma Aldrich. A-549, U-87 and HDF cells were purchased from the American Type Culture Collection (ATCC) through LGC Standards (Lomianki). KB, Hep-G2 and U-87 cells were cultured in EMEM medium while HeLa cells were grown in RPMI 1640 medium, A-549 cells in F-12K medium and HDF cells in Fibroblasts Growth Medium. Each medium was supplemented with $10 \%$ fetal bovine serum, $1 \%$ L-glutamine and $1 \%$ penicillin/streptomycin solution. All cultures were maintained at $37^{\circ} \mathrm{C}$ in a humidified atmosphere containing $5 \% \mathrm{CO}_{2}$.

\subsection{Prepolymer and Polymer Synthesis}

Copolymers were obtained by two-step melt polycondensation of betulin disuccinate and sebacic acid (SA) according to the procedure described earlier [6]. Betulin disuccinate and sebacic acid mixed in defined ratios (sebacic acid content in copolymers was 20, 40, 60 and $80 \mathrm{wt} \%$, respectively) were refluxed in acetic anhydride (1:10, w/v) under nitrogen flow for $40 \mathrm{~min}$. After this time, the excess of acetic anhydride and acetic acid formed in reaction were removed under vacuum. The remaining diacyl derivative of disuccinate betulin and SA (prepolymer) was heated at $150{ }^{\circ} \mathrm{C}$ for $2 \mathrm{~h}$ with constant stirring under vacuum $(0.1 \mathrm{~mm} \mathrm{Hg})$ and nitrogen. Copolymers (polyDBB_SEB) in form of a solid materials were obtained with a yield of over $90 \%$. The obtained polymers were stored in a freezer.

FT-IR: v $=2941 \mathrm{~cm}^{-1}(\mathrm{~m}, \mathrm{vc}-\mathrm{H}), 2844 \mathrm{~cm}^{-1}(\mathrm{w}, \mathrm{Vc}-\mathrm{H}), 1827 \mathrm{~cm}^{-1}(\mathrm{~m}, \mathrm{vc}=\mathrm{O}), 1724 \mathrm{~cm}^{-1}(\mathrm{~s}, \mathrm{vc}=\mathrm{O}), 1034 \mathrm{~cm}^{-1}$ (vc-o).

${ }^{1} \mathrm{H}$ NMR $\left(600 \mathrm{MHz}, \mathrm{CDCl}_{3}, \delta\right): 4.68\left(1 \mathrm{H}, \mathrm{d}, \mathrm{C}_{29}-\mathrm{H}_{\mathrm{a}}\right) ; 4.59\left(1 \mathrm{H}, \mathrm{d}, \mathrm{C}_{29}-\mathrm{H}_{\mathrm{b}}\right), 4.50\left(1 \mathrm{H}, \mathrm{t}, \mathrm{C}_{3}-\mathrm{H}_{\alpha}\right) ; 4.30$ $\left(1 \mathrm{H}, \mathrm{d}, \mathrm{C}_{28}-\mathrm{H}_{\mathrm{a}}\right) ; 3.88\left(1 \mathrm{H}, \mathrm{d}, \mathrm{C}_{28}-\mathrm{Hb}\right) ; 2.82-2.78\left(4 \mathrm{H}, \mathrm{m},-\mathrm{OCOOC}-\mathrm{CH}_{2}-\mathrm{CH}_{2}-\mathrm{COO}-\right)$; 2.71-2.64 (4H, m, OCOOC- $\left.\mathrm{CH}_{2}-\mathrm{CH}_{2}-\mathrm{COO}-\right) ; 2.52-2.40\left(1 \mathrm{H}, \mathrm{C}_{19}-\mathrm{H}\right.$ and $4 \mathrm{H}$ in $\left.\mathrm{SA}\right) ; 2.18$ (end groups); $1.96\left(1 \mathrm{H}, \mathrm{m}, \mathrm{C}_{21}-\right.$ $\left.\mathrm{H}_{\mathrm{a}}\right) ; 1.82\left(1 \mathrm{H}, \mathrm{d}, \mathrm{C}_{16}-\mathrm{H}_{\mathrm{a}}\right) ; 1.76\left(1 \mathrm{H}, \mathrm{t}, \mathrm{C}_{22}-\mathrm{H}_{\mathrm{a}}\right) ; 1.68\left(3 \mathrm{H}, \mathrm{s}, \mathrm{C}_{30}-\mathrm{H}_{3}\right) ; 1.67-1.54\left(7 \mathrm{H}, \mathrm{m}, \mathrm{C}_{15}-\mathrm{H}_{\mathrm{a}}, \mathrm{C}_{1}-\mathrm{H}_{\mathrm{a}}, \mathrm{C}_{12}-\right.$ $\left.\mathrm{H}_{\mathrm{a}}, \mathrm{C}_{13}-\mathrm{H}_{\mathrm{a}}, \mathrm{C}_{2}-\mathrm{H}_{\mathrm{a}, \mathrm{b}}, \mathrm{C}_{18}-\mathrm{H}\right) ; 1.51\left(1 \mathrm{H}, \mathrm{m}, \mathrm{C}_{6}-\mathrm{H}_{\mathrm{a}}\right) ; 1.45-1.35\left(5 \mathrm{H}, \mathrm{m}, \mathrm{C}_{6}-\mathrm{H}_{b}, \mathrm{C}_{11}-\mathrm{H}_{\mathrm{a}}, \mathrm{C}_{21}-\mathrm{H}_{b}, \mathrm{C}_{7}-\mathrm{H}_{\mathrm{a}} \mathrm{b} ; 8 \mathrm{H}\right.$ in 
SA); 1.29 (1H, d, C9-H); 1.26-1.17 (2H, m, $\left.\mathrm{C}_{11}-\mathrm{H}_{\mathrm{b}}, \mathrm{C}_{16}-\mathrm{Hb}\right) ; 1.13-1.04\left(3 \mathrm{H}, \mathrm{m}, \mathrm{C}_{22}-\mathrm{H}_{\mathrm{b}}, \mathrm{C}_{12}-\mathrm{H}_{\mathrm{b}}, \mathrm{C}_{15}-\mathrm{Hb}\right) ; 1.02$ $\left(3 \mathrm{H}, \mathrm{s}, \mathrm{C}_{25}-\mathrm{H}_{3}\right) ; 0.97\left(3 \mathrm{H}, \mathrm{s}, \mathrm{C}_{27}-\mathrm{H}_{3}\right) ; 0.94-0.92\left(1 \mathrm{H}, \mathrm{m}, \mathrm{C}_{1}-\mathrm{H}_{b}\right) ; 0.88-0.80\left(9 \mathrm{H}, \mathrm{s}, \mathrm{C}_{26}-\mathrm{H}_{3}, \mathrm{C}_{23}-\mathrm{H}_{3}, \mathrm{C}_{24}-\mathrm{H}_{3}\right)$; $0.78(1 \mathrm{H}, \mathrm{d}, \mathrm{C} 5-\mathrm{H})$.

${ }^{13} \mathrm{C}$ NMR (150 MHz, $\left.\mathrm{CDCl}_{3}, \delta\right): 171.95\left(\mathrm{C}_{\mathrm{q}}, \mathrm{C}(\mathrm{O}) \mathrm{O}\right) ; 167.94\left(\mathrm{C}_{\mathrm{q}}, \mathrm{C}(\mathrm{O}) \mathrm{OC}(\mathrm{O})\right) ; 150.03\left(\mathrm{C}_{\mathrm{q}}, \mathrm{C}-20\right)$; 110,0 ( $\left.\mathrm{CH}_{2}, \mathrm{C}-29\right) ; 81.73$ (CH, C-3); $63.32\left(\mathrm{CH}_{2}, \mathrm{C}-28\right), 55.36(\mathrm{CH}, \mathrm{C}-5) ; 50.25(\mathrm{CH}, \mathrm{C}-9) ; 48.78(\mathrm{CH}, \mathrm{C}-$ 18), 47.68 (CH, C-19); 46.40 (C, C-17); $42.68\left(\mathrm{C}_{\mathrm{q}}, \mathrm{C}-14\right) ; 40.88\left(\mathrm{C}_{\mathrm{q}}, \mathrm{C}-8\right) ; 38.33\left(\mathrm{CH}_{2}, \mathrm{C}-1\right) ; 37.84\left(\mathrm{C}_{\mathrm{q}}, \mathrm{C}-\right.$ $10) ; 37.58(\mathrm{CH}, \mathrm{C}-13) ; 37.03\left(\mathrm{C}_{9}, \mathrm{C}-4\right) ; 34.48\left(\mathrm{CH}_{2}, \mathrm{C}-22\right) ; 34.07\left(\mathrm{CH}_{2}, \mathrm{C}-7\right) ; 30.35-30.18\left(\mathrm{CH}_{2} \mathrm{C}(\mathrm{O}) \mathrm{OC}(\mathrm{O})\right)$; $29.70\left(\mathrm{CH}_{2}, \mathrm{C}-21\right) ; 29.54\left(\mathrm{CH}_{2}, \mathrm{C}-16\right) ; 28,89$ and $28.60\left(\mathrm{CH}_{2} \mathrm{C}(\mathrm{O}) \mathrm{O}\right) ; 27.95\left(\mathrm{CH}_{3}, \mathrm{C}-23\right) ; 27.0\left(\mathrm{CH}_{2}, \mathrm{C}-15\right)$; $25.13\left(\mathrm{CH}_{2}, \mathrm{C}-12\right) ; 23.62\left(\mathrm{CH}_{2}, \mathrm{C}-2\right) ; 20.78\left(\mathrm{CH}_{2}, \mathrm{C}-11\right) ; 19.12\left(\mathrm{CH}_{3}, \mathrm{C}-30\right) ; 18.13\left(\mathrm{CH}_{2}, \mathrm{C}-6\right) ; 16.51\left(\mathrm{CH}_{3}\right.$, $\mathrm{C}-25) ; 16.13\left(\mathrm{CH}_{3}, \mathrm{C}-26\right) ; 16.0\left(\mathrm{CH}_{3}, \mathrm{C}-24\right) ; 14.74\left(\mathrm{CH}_{3}, \mathrm{C}-27\right)$.

\subsection{Characterization of Polyanhydrides}

${ }^{1} \mathrm{H}$ NMR and ${ }^{13} \mathrm{C}$ NMR spectra of polymers in $\mathrm{CDCl}_{3}$ were recorded on a Varian $600 \mathrm{MHz}$ spectrometer with TMS as an internal standard. Infrared (FT-IR) spectra were recorded by means of a PerkinElmer Spectrum Two Spectrometer. Molecular weights of polyanhydrides were determined in methylene chloride by gel-permeation chromatography (GPC) using Agilent Technologies Infinity 1260 chromatograph equipped with a refractive index detector and calibrated with polystyrene standards. Molecular weights were also calculated from ${ }^{1} \mathrm{H}$ NMR spectra. Thermal analyses were performed using a $822^{2}$ DSC Mettler Toledo differential scanning calorimeter. Samples were tested in temperature range from $-60^{\circ} \mathrm{C}$ to $250{ }^{\circ} \mathrm{C}$ at a heating rate of $10^{\circ} \mathrm{C} / \mathrm{min}$.

\subsection{Hydrolytic Degradation of Copolymers}

Hydrolytic degradation experiments were performed in a phosphate buffer solution of $\mathrm{pH} 7.4$ (PBS) at $37^{\circ} \mathrm{C}$. The hydrolytic degradation was monitored by the content of anhydride groups in test samples. Copolymers solid samples (approximately $0.1 \mathrm{~g}$ ) were placed in the weighed filters. Then, the filters with copolymers were placed in glass vials containing $15 \mathrm{~mL}$ of PBS. The vials were incubated at $37^{\circ} \mathrm{C}$ for various time (from $1 \mathrm{~h}$ to 14 days). After incubation, the buffer were decanted. The remaining samples were rinsed with distilled water, dried to constant weight in vacuum oven, weighted to the nearest $0.0001 \mathrm{~g}$ and tested by ${ }^{1} \mathrm{H}$ NMR to calculate the content of anhydride groups.

The ratio of anhydride groups to the sum of anhydride and ester groups in the polyanhydride $(\mathrm{A} / \mathrm{A}+\mathrm{E})$ was calculated using the formula:

$$
\mathrm{A} / \mathrm{A}+\mathrm{E}=\mathrm{Isac} /(\mathrm{Isac}+\mathrm{IE})
$$

where IsAc represents the intensity of proton signals of the methylene group in the anhydride moiety with a chemical shift $(\delta)$ of $2.82-2.77$ ppm, IE represents the intensity of the proton signals of the methylene group in the ester moiety with a chemical shift (ठ) of $2.74-2.64 \mathrm{ppm}$.

\subsection{Cytostatic Activity of Polyanhydrides}

For the determination of the cytotoxic activity of test compounds, the protein-staining sulforhodamine B (SRB) assay was employed. The SRB method has been assessed by the National Cancer Institute (USA) as suitable for the in vitro anti-tumour screening [8]. The SRB assay estimates cell densities based on the measurement of cellular protein content. For the SRB assay, $100 \mu \mathrm{L}$ of diluted cell suspension containing approximately $10^{4}$ cells was added to the wells of 96-well plates. After $24 \mathrm{~h}$, when a partial monolayer was formed, the supernatant was aspirated and $100 \mu \mathrm{L}$ medium containing test compounds (copolymers) at six different concentrations $(0.1,0.2,1,2,10$ and 20 $\mu \mathrm{g} / \mathrm{mL}$ ) was added to the cells. Stock solutions of test compounds were prepared in DMSO and the concentration of DMSO in the assay did not exceed $0.1 \%$ which was found to be nontoxic to applied cell lines. After incubation for $72 \mathrm{~h}, 25 \mu \mathrm{L}$ of $50 \%$ trichloroacetic acid was added to each well and the plates were incubated for $1 \mathrm{~h}$ at $4{ }^{\circ} \mathrm{C}$. After that, the plates were washed with distilled water to remove traces of medium and were air-dried. Then, the dried plates were stained with $100 \mu \mathrm{L} 0.4 \%$ SRB (prepared in 1\% acetic acid) for $30 \mathrm{~min}$ at room temperature. Unbound dye was removed by rapid 
washing with $1 \%$ acetic acid and the plates were air-dried overnight. Finally, the protein-bound dye was dissolved in $100 \mu \mathrm{L}$ of $10 \mathrm{mM}$ unbuffered Tris and the absorbance was read at $490 \mathrm{~nm}$.

\subsection{Preparation and Characterization of Microspheres}

Polyanhydrides based on DBB and SA were used to obtain polymer microspheres. Microspheres were prepared by solvent evaporation from polymer solution dispersed in aqueous phase, according to previous reports [6]. The polymer solution in methylene chloride $(20 \mathrm{~mL}$, concentration $50 \mathrm{mg} / \mathrm{mL})$ was emulsified in $400 \mathrm{~mL}$ of aqueous solution $(1 \% \mathrm{w} / \mathrm{w})$ of poly(vinyl alcohol) (PVAl $88 \%$ hydrolyzed, MW = 88,000 g/mol), using ULTRA-TURRAX T18 homogenizer, for $30 \mathrm{~s}$. The speed of homogenizer was $3000 \mathrm{rpm}$. The emulsion was stirred with a magnetic stirrer at $1100 \mathrm{rpm}$ at room temperature for $2.5 \mathrm{~h}$ to evaporate the organic solvent. After that microspheres were collected by centrifugation at $5000 \mathrm{rpm}$ for $5 \mathrm{~min}$, washed 3 times with distilled water, lyophilized and stored in freezer. Size and size distribution of particles were estimated using optical microscope. The morphological characterization of microspheres was carried out using a Phenom ProX scanning electron microscope.

\section{Results and Discussion}

\subsection{Synthesis and Characterization of Betulin-Based Polyanhydrides}

Polyanhydrides were obtained by melt polycondensation of betulin disuccinate and sebacic acid with the use of acetic anhydride. Sebacic acid was selected as comonomer. The content of SA in copolymers ranged from 20 to $80 \mathrm{wt} \%$. The use of DBB was intended to obtain polyanhydrides with potential antitumor activity and the use of SA as a comonomer was intended to increase the crystallinity. The obtained polymers were solid materials, amorphous when containing more DBB, and crystalline when containing more sebacic acid. To determine the structure of polyanhydrides, FT-IR, ${ }^{1} \mathrm{H}$ NMR and ${ }^{13} \mathrm{C}$ NMR spectra were made. A successful synthesis of polyanhydrides was confirmed by the formation an anhydride bond. Two characteristic peaks in the carbonyl region of the FT-IR spectra at $1724 \mathrm{~cm}^{-1}$ and $1827 \mathrm{~cm}^{-1}$ confirmed the formation of anhydride bonds.

In ${ }^{1} \mathrm{H}$ NMR spectra the signals at $\delta=2.82-2.78 \mathrm{ppm}$ and at $\delta=2.48-2.40 \mathrm{ppm}$ are visible, which could be assigned to methylene protons close to anhydride groups in DBB and SA part, respectively. The presence of this signals in ${ }^{1} \mathrm{H}$ NMR spectrum confirmed the formation of the polyanhydride. The ${ }^{13} \mathrm{C}$ NMR spectra of copolymers showed signals assigned to carbonyl carbon atoms in anhydride $(\delta=$ $167.94 \mathrm{ppm})$ and ester groups $(\delta=171.95 \mathrm{ppm})$ as well as two different signals of methylene carbon atoms next to ester $(\delta=28.89 \mathrm{ppm}$ and $\delta=28.89 \mathrm{ppm})$ and anhydride $(\delta=30.35-30.18 \mathrm{ppm})$ groups respectively. The rest of ${ }^{1} \mathrm{H}$ NMR and ${ }^{13} \mathrm{C}$ NMR signals were assigned to the relevant polyDBB_PEG protons and carbons based on our previous work [6]. Molecular weight of copolymers were calculated from ${ }^{1} \mathrm{H}$ NMR and determined by GPC. The molecular weights values obtained from NMR spectra and GPC were similar and ranged from 7000 to 20,000.

\subsection{Hydrolytic Degradation of Polymers}

Hydrolytic degradation was carried out in PBS ( $\mathrm{pH} 7.4$ ) at $37^{\circ} \mathrm{C}$, in order to determine the disappearance of anhydride bonds. The results are show in Figure 1.

${ }^{1} \mathrm{H}$ NMR spectra of samples remaining after different degradation times revealed the presence of betulin disuccinate and sebacic acid among the degradation products. No hydrolysis of ester bonds in DBB was observed, similar to the degradation of polyDBB [6]. In the ${ }^{1} \mathrm{H}$ NMR spectra of the degradation products, the signals at $\delta=3.18 \mathrm{ppm}, \delta=3.33 \mathrm{ppm}$ and $\delta=3.79 \mathrm{ppm}$ assigned to methylene and methine protons next to hydroxyl groups were not observed. For obtained copolymers degradation rate is strongly depended on the content of the comonomer (SA).

Homopolymer from betulin disuccinate, obtained in our previous work [6], due to the strong hydrophobicity, degrade relatively slowly. Under physiological conditions degrades completely in about 14 days. During this time, complete disappearance of anhydride bonds in the sample was observed. Copolymers based on DBB and SA, degrades faster in compare to polyDBB. The results 
shows that the degradation rate increase with the increase of content of comonomer (SA) in polyanhydrides. Almost all copolymers degrades completely within five days.

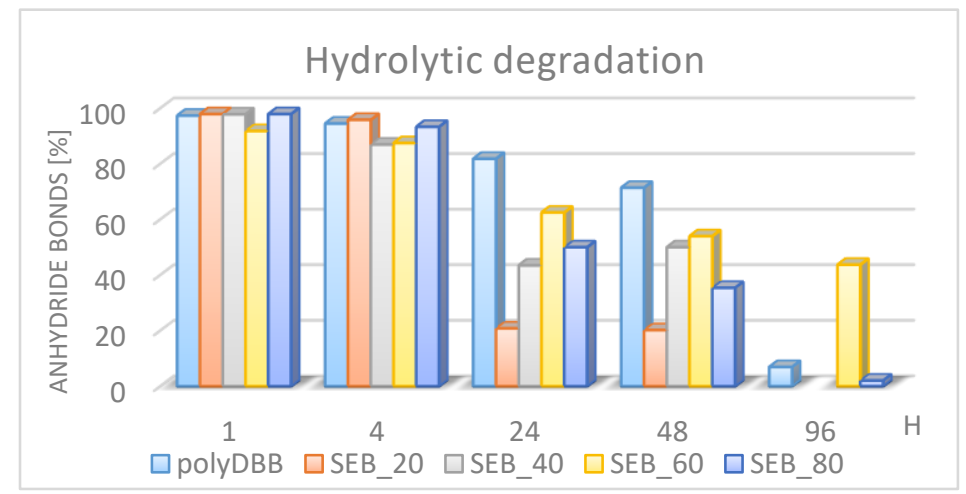

Figure 1. Anhydride bond loss of copolymers based on DBB and SA.

\subsection{Cytostatic Activity of Polyanhydrides}

Polyanhydrides containing DBB and SA were studied to determine their cytostatic activity against selected cancer cell lines. Cell lines representing cervix, breast, lung, liver, central nervous system and nasopharynx tumors were used in these studies to find concentrations causing inhibition of cell growth in culture by $50 \%$ ( $\mathrm{IC}_{50}$ ). The $\mathrm{IC}_{50}$ values obtained for DBB, polyDBB and copolymers are listed in Table 1. HDF cells lines were used as non-proliferative cells, to compare results from human cancer cell lines and to establish selectivity between cancer and non-cancer cells. Table 1 also includes the results obtained for monomer (DBB) and polyDBB, described earlier [6].

Table 1. Cytostatic activity of polyanhydrides against various cancer cell lines as well as a normal control (HDF), expressed as $\mathrm{IC}_{50}$ a.

\begin{tabular}{ccccccc}
\hline \multirow{2}{*}{ Compound } & \multicolumn{5}{c}{ Cytostatic Activity IC50 $[\mu \mathrm{g} / \mathrm{mL}]$} \\
\cline { 2 - 7 } & HeLa & A-549 & U-87 MG & KB & HepG2 & HDF \\
\hline DBB & $8.25 \pm 0.81$ & $7.09 \pm 0.01$ & $7.37 \pm 0.26$ & $7.17 \pm 0.93$ & $8.02 \pm 0.04$ & $14.80 \pm 0.06$ \\
polyDBB & $16.23 \pm 0.72$ & $16.19 \pm 0.31$ & $16.07 \pm 0.02$ & $17.81 \pm 0.03$ & $15.93 \pm 0.12$ & $27.13 \pm 0.01$ \\
SEB_20 & $4.61 \pm 0.03$ & $4.15 \pm 0.24$ & $4.99 \pm 0.05$ & $4.28 \pm 0.01$ & $4.15 \pm 0.01$ & $7.31 \pm 1.92$ \\
SEB_40 & $8.22 \pm 0.09$ & $8.15 \pm 0.01$ & $8.12 \pm 0.91$ & $8.04 \pm 0.03$ & $8.77 \pm 0.23$ & $13.55 \pm 0.22$ \\
SEB_60 & $8.10 \pm 0.74$ & $8.29 \pm 0.55$ & $8.41 \pm 0.01$ & $8.28 \pm 0.01$ & $8.39 \pm 0.16$ & $8,22 \pm 1.17$ \\
SEB_80 & $11.48 \pm 0.22$ & $11.29 \pm 0.18$ & $11.06 \pm 0.37$ & $11.39 \pm 0.51$ & $11.12 \pm 0.46$ & $18.01 \pm 0.02$ \\
\hline
\end{tabular}

${ }^{\text {a }} \mathrm{N}=3$ (t-test), $p<0.05$.

Cytostatic tests indicated the effectiveness of obtained copolymers in inhibition of growth of cancer cells $\left(\mathrm{IC}_{50}<12 \mu \mathrm{g} \mathrm{ml}^{-1}\right)$, with limited cytotoxicity towards normal cells. IC 50 values calculated for copolymers were lower than these determined for polyDBB, which is associated with faster hydrolytic degradation and release of more betulin disuccinate during the experiment. The results shows that cytostatic activity of polyanhydrides based on betulin disuccinate can be modified by changing the kind of comonomer and its content, allowing to optimize the degradation rate and tailor the period of cytotoxicity. Copolymers based on betulin disuccinate, just like polyDBB, can be used as a degradation-based delivery systems for DBB or combined with other chemotherapeutic agents can lead to a synergistic therapeutic effect in cancer treatment.

\subsection{Microspheres Preparation and Characterization}

In order to use copolymers based on DBB and SA in controlled drug delivery systems, attempts were made to obtain polymer microspheres. Microspheres were prepared by an emulsion $(\mathrm{O} / \mathrm{W})$ solvent evaporation technique using poly(vinyl alcohol) as stabilizing agent. Obtained particles are spherical and have smooth surface (Figure 2). The diameter of the microspheres were within the range from 15 to $30 \mu \mathrm{m}$. 

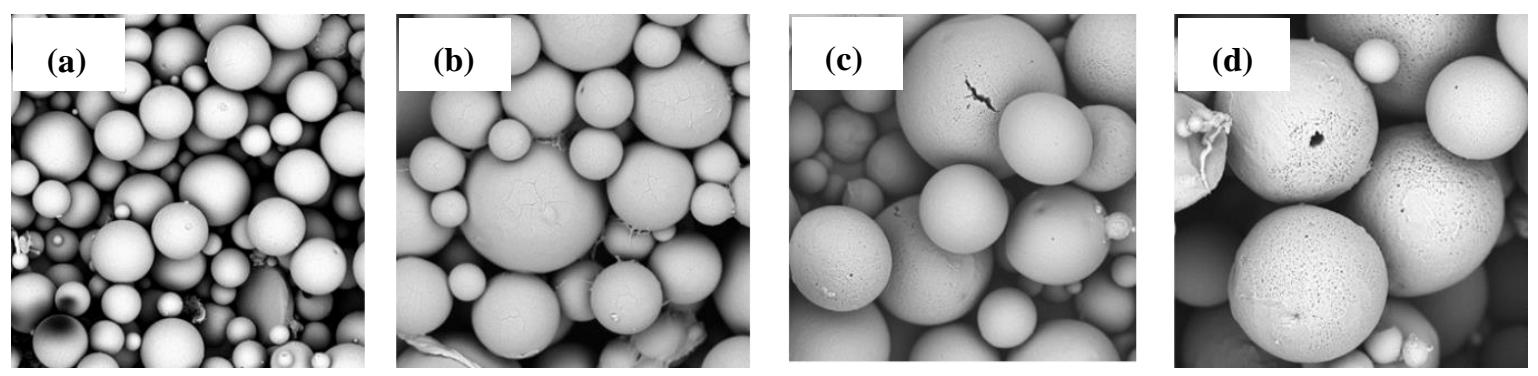

Figure 2. SEM images of microspheres obtained from: (a) polyDBB_SEB_20; (b) polyDBB_SEB_40; (c) polyDBB_SEB_60 and (d) polyDBB_SEB_80, by using homogenization speed of $3000 \mathrm{rpm}$.

Obtained microspheres may be considered as vehicles for biologically active compound. They can be used to encapsulate, protect and control release of a wide range of drugs, and they can be easily injected into the body.

Author Contributions: Conceptualization, D.N. and K.J.; methodology, D.N. and K.J; investigation, D.N., B.B.C. and P.R.; resources, D.N.; data curation, D.N. and K.J.; writing - original draft preparation, D.N.; writingreview and editing, D.N. and K.J.; visualization, D.N.; supervision, K.J. All authors have read and agreed to the published version of the manuscript.

Funding: This research was funded by the Polish Budget Founds for Scientific Research in 2020 as core funding for R\&D activities in the Silesian University of Technology-funding for young scientists, grant number 04/040/BKM20/0133.

Conflicts of Interest: The authors declare no conflict of interest.

\section{References}

1. Jeromenok, J.; Böhlmann, W.; Antonietti, M.; Weber, J. Intrinsically Microporous Polyesters From BetulinToward Renewable Materials for Gas Separation Made From Birch Bark. Macromol. Rapid Commun. 2011, 32, 1846-1851, doi:10.1002/marc.201100532.

2. Paduch, R.; Kandefer-Szerszeń, M.; Trytek, M.; Fiedurek, J. Terpenes: Substances useful in human healthcare. Arch. Immunol. Ther. Exp. 2007, 55, 315-327, doi:10.1007/s00005-007-0039-1.

3. Alakurtti, S.; Mäkelä, T.; Koskimies, S.; Yli-Kauhaluoma, J., Pharmacological properties of the ubiquitous natural product betulin. Eur. J. Pharm. Sci. 2006, 29, 1-13, doi:10.1016/j.ejps.2006.04.006.

4. Jeromenok, J.; Böhlmann, W.; Jäger, C.; Weber, J. Carbon Dioxide Adsorption in Betulin-Based Micro- and Macroporous Polyurethanes. ChemistryOpen 2013, 2, 17-20, doi:10.1002/open.201200045.

5. Zhao, J.; Schlaad, H.; Weidner, S.; Antonietti, M. Synthesis of terpene-poly(ethylene oxide)s by $t$-BuP4promoted anionic ring-opening polymerization. Polym. Chem. 2012, 3, 1763-1768, doi:10.1039/C1PY00388G.

6. Niewolik, D.; Krukiewicz, K.; Bednarczyk-Cwynar, B.; Ruszkowski, P.; Jaszcz, K. Novel polymeric derivatives of betulin with anticancer activity. RSC Adv. 2019, 9, 20892-20900, doi:10.1039/C9RA03326B.

7. Domb, A.J.; Kumar, N.; Ezra, A. Wiley \& Sons Inc.: Hoboken, NJ, USA, 2011.

8. Skehan, P.; Storeng, R.; Scudiero, D.; Monks, A.; McMahon, J.; Vistica, D.; Warren, J.T.; Bokesch, H.; Kenney, S.; Boyd, M.R. New Colorimetric Cytotoxicity Assay for Anticancer-Drug Screening. J. Natl. Cancer Inst. 1990, 82, 1107-1112, doi:10.1093/jnci/82.13.1107.

Publisher's Note: MDPI stays neutral with regard to jurisdictional claims in published maps and institutional affiliations.

(C) 2020 by the authors. Submitted for possible open access publication under the terms and conditions of the Creative Commons Attribution (CC BY) license (http://creativecommons.org/licenses/by/4.0/). 